\title{
Nephila clavata L. Koch, the Joro Spider of East Asia, newly recorded from North America (Araneae: Nephilidae)
}

E. Richard Hoebeke, Wesley Huffmaster, Byron J Freeman

Nephila clavata L. Koch, known as the Joro spider and native to East Asia (Japan, China, Korea, and Taiwan), is newly reported from North America. Specimens from several locations in northeast Georgia were collected from around residential properties in Barrow, Jackson, and Madison counties in late October and early November 2014. These are the first confirmed records of the species in the New World. Our collections, along with confirmed images provided by private citizens, suggest the Joro spider is established in northeast Georgia. Genomic sequence data for the $\mathrm{COI}$ gene obtained from two specimens conforms to published sequences for $N$. clavata, providing additional confirmation of species identity. Known collection records are listed and mapped using geocoding. Our observations are summarized along with published background information on biology in Asia and we hypothesize on the invasion history and mode of introduction into North America. Recognition features are given and photographic images of the male and female are provided to aid in their differentiation from the one native species of the genus (Nephila clavipes) in North America. 
2 Nephila clavata L. Koch, the Joro Spider of East Asia, newly recorded from North America 3 (Araneae: Nephilidae)

4

E. Richard Hoebeke ${ }^{1}$, Wesley Huffmaster ${ }^{2}$ and Byron J. Freeman ${ }^{3}$

${ }^{1}$ Georgia Museum of Natural History and Department of Entomology, University of Georgia, Athens, GA 30602

${ }^{2} 124$ Circle D Drive, Colbert, GA 30628

${ }^{3}$ Georgia Museum of Natural History and Eugene P. Odum School of Ecology, University of Georgia, Athens, GA 30602

Corresponding author: E. Richard Hoebeke, Georgia Museum of Natural History, University of Georgia, Athens, GA 30602, e-mail: rhoebeke@uga.edu

\section{Keywords}

Araneae, Nephilidae, non-native, Georgia, descriptive notes, distribution, genetic analysis, new record, citizen science, COI.

\section{INTRODUCTION}

Golden orb-web spiders of the genus Nephila are pantropical in distribution (Su et al. 2011), exhibit extreme sexual size dimorphism (Kuntner \& Coddington 2009), and construct exceptionally large and impressive orb webs (Kuntner, Gregoric \& Li, 2010). Up until recently, the genus Nephila has been variously positioned by workers in either the family Araneidae or Tetragnathidae (see Pan et al., 2004). Some morphological, behavorial, and molecular evidence supports the elevation of the subfamily Nephilinae to family rank (Kuntner, 2006; Harvey, Austin \& Adams, 2007; Kuntner, Coddington \& Hormiga, 2008; Su et al., 2011; Kuntner et al., 2013), while other phylogenetic analyses support the inclusion of Nephila in the monophyletic family Tetragnathidae (Dimitrov \& Hormiga, 2009). A recent study of the species composition of the Tetragnathidae and phylogenetic relationships of its various lineages, including Nephila and its relatives (Alvarez-Padilla et al., 2009) concluded that nephilids are not closely related to tetragnathids as previously thought, that their position remains ambiguous, and that genetic analyses found Nephilidae to be sister to the Araneidae.

Since the early 1980s, accelerated global mobility of humans and their commodities, coupled with human-induced habitat destruction, alteration and fragmentation, has allowed countless species of exotic animals and plants to gain a foothold in distant locations (Wheeler and Hoebeke, 2009; Mack et al., 2000). Increasing trade with Asia and other Pacific rim countries has favored the arrival and establishment of many new insects and other arthropods from the eastern Palearctic Region into North 
41 America. Spiders, largely due to their secretive habits and ability to hitchhike on various commodities,

42 linked with the speed with which these items are transported to North American ports, can be easily

43 introduced inadvertently into novel habitats. Detection of these immigrant species can sometimes be

44 challenging and depends on the availability of taxonomists who can accurately identify them. In

45 addition to the utilization of traditional morphological characters for species identification and

46 differentiation, DNA barcoding (i.e., use of a short genetic marker - mitochondrial gene cytochrome

47 oxidase I - in an organism's DNA) has become another important and universal tool in confirming the

48 identity of animals not otherwise easily identifiable (Hebert et al., 2003; Blaxter, 2004; Waugh, 2007).

49 In this paper, we provide the first collection records and photographic evidence confirming the

50 occurrence of the East Asian N. clavata L. Koch in North America. Descriptive notes are given to

51 facilitate the recognition of $N$. clavata in the Nearctic Region. We review literature on biology and

52 habitat in its native range, and aligned COI sequences recovered in this study are compared with

53 published sequences for Nephila clavata.

54

55

56

57

58

59

60

61

62

63

64

65

66

67

68

69

70

71

\section{MATERIALS AND METHODS}

In late September 2014, one of us (WH) discovered a large, extremely colorful, but unrecognized female spider in an expansive web spun between upper tree branches about 2.5 meters above-ground at a site in Madison Co. (Colbert), GA. The spider's identity was confirmed (by ERH) using taxonomic references on Asian spiders (cited herein), examining and comparing the male genital structures (palpal organ) with that illustrated in the primary literature, and by comparing specimens in hand with images posted on the Internet for this common eastern Palearctic species.

This remarkable discovery prompted us to find a way to determine if other people in northeast Georgia had encountered this large, attractive orb-weaving spider. Almost as soon as a press release appeared in a local newspaper in late October - calling attention to the first-time detection of this spider in North America with a color image - we heard almost immediately from several concerned citizens throughout a 3-county area of northeast Georgia.

Over the course of the next week to 10-days, we had confirmed sightings from at least 9 locations (see locality data under North American records). With the exception of only a few sightings, 
we were able to collect specimens (females) from all locations. On one occasion at a small community park (Braselton Park) in Braselton, GA (November 4), we (ERH and BJF) collected specimens (2

A genetic analysis (by BJF) involved the sequencing of 2 female specimens from Jackson (GMNHTC 12242) and Madison (GMNHTC 12241) counties. Genomic DNA was extracted from single spider legs previously preserved in $95 \%$ ethanol, using a Chelex ${ }^{\circledR} 100$ Resin and proteinase-k solution, incubated overnite at $55^{\circ} \mathrm{C}$. (Casquet et al. 2012). The cytochrome C oxidase subunit I (COI) mitochondrial gene was amplified by polymerase chain reaction (PCR) using the primer combinations of LCO1490: 5' -GGTCAACAAATCATAAAGATATATTGG-3' and HCO2198: 5'-

TAAACTTCAGGGTGACCAAAAAAATCA-3' (Folmer et al. 1994, Su et al. 2011), and recovered a 639 base pair fragment with a starting motif of TTGGTACTGCAATAAGAGTA. PCR reactions followed conditions reported in Wares et al. (2001). PCR products were assayed by electrophoresis using a 1.0\% agarose gel and sequencing was performed by Macrogen (Macrogen, USA; available at https://www.macrogenusa.com/). Sequence files were aligned using CodonCode Aligner, and Geneious version 8.05 (created by Biomatters, available at http://www.geneious.com/) was used to visualize sequence data and compared with published sequences for Nephilidae.

Voucher specimens of N. clavata are deposited in the Collection of Arthropods, Georgia Museum of Natural History (UGCA), and specimens sequenced are also catalogued in the Georgia Museum of Natural History Genomic Collection (GMNHTC) University of Georgia, Athens, GA. In addition, an ArcGIS map of collection locations of N. clavata in northeast Georgia is provided.

\section{RESULTS}

Nephila clavata L. Koch

(Figs. 1A-D, 2, 3)

Spiders of the genus Nephila are found throughout the tropical and subtropical regions of the world (Kuntner et al., 2013). According to the World Spider Catalog (2014), the genus is comprised of 38 species and subspecies. However, Kuntner (2005) and Kuntner \& Coddington (2009) note that of the 
102150 available species-level names, only 15 Nephila species are actually valid and known globally and 103 that all recent descriptions probably represent synonyms.

104 In the New World, the genus is represented by only two extant species. Nephila clavipes (L.), 105 often called the "banana spider" or the "golden silk spider," is found throughout Florida, the West 106 Indies, as far north as North Carolina, across the Gulf States, through Central America, and into South 107 America as far south as Argentina (Weems \& Edwards, 2004). Nephila sexpuctata Giebel, endemic to 108 the Neotropics, occurs in a limited range in southern South America (Brazil, Paraguay, Argentina). Nephila clavata, native to East Asia, is referred to as the Joro spider in Japan (Japanese name: 110 jorō-gumo) and the Mudang spider in Korea (Korean name: mudang gumi). Literally translated, "Jorō111 gumo" means "entangling or binding bride" or alternatively "whore spider," while the Korean name 112 translates to "shaman" or "fortune teller" spider.

113 Descriptive notes. Nephila clavata females can be readily distinguished from those of our 114 native $N$. clavipes by their unique coloration (opisthosoma bright yellow, when alive, with broad, 115 horizontal bluish-green bands on the dorsum, large red markings on the venter, and long, black legs 116 with yellow-orange bands). In contrast, the female of Nephila clavipes can be readily recognized by its 117 color pattern alone - the silvery carapace, yellow spots on a dull orange to tan cylindrical opisthosoma, 118 brown and orange-banded legs, plus the exaggerated hair brushes on the tibial segment of legs I, II, and 119 IV (Weems \& Edwards, 2004). Among other large orb-weaving spiders rivaling N. clavata in size, 120 only the yellow and black garden spider, Argiope aurantia (F.), could be easily confused. However, it 121 differs in body coloration (opisthosoma with striking yellow or orange markings on a black 122 background) and in web architecture (circular web with a dense zigzag of silk, known as a 123 stabilimentum, in the center).

124 The female (Figs. 1A-C) of $N$. clavata can be characterized by the following combination of 125 characters: Length: 17-30 mm; carapace of the prostoma dark brown with dense, golden to silvery126 white vestiture; sternum dark brown with a trapezoidal yellow spot in the median area of the anterior 127 half; legs black except for yellow-orange annulations at middle of tibia and at apical two-thirds of 128 femur; base of metatarsus black in some specimens while yellowish at extreme base in others; tarsus 129 varies from black to slightly orangish; palpi yellow-orange, with terminal segment black apically; 130 opisthosoma ovoid-cylindrical with its dorsum (Fig. 1A) bright yellow (when alive) with five narrow to 131 broad bluish-green horizontal bands; venter of opisthosoma (Fig. 1C) with anterior half marked with 
132 irregular black-brown oblique stripes and posterior half with two broad, oblique, red markings anterior 133 to the spinnerets.

134 The male (Fig. 1D) is significantly smaller than the female, measuring only 4-8 $\mathrm{mm}$ in length.

135 The prostoma is light brown with two dark brown longitudinal bands on both sides. The opisthosoma is 136 elongate-oval with its dorsum greenish-brown with two yellowish longitudinal stripes on both sides of 137 the dark brown median line. The palpal organ of the male is described and illustrated by Feng (1990:

138 96, Figs. 2-3); Zhu, Song, \& Zhang (2003: 76, Fig. 32, I, J); Tanikawa (2007: 95, Figs. 764, 766), and 139 Zhu \& Zhang (2011: 194, Fig. 136, I, J).

140 The anatomical characters given under descriptive notes above are adapted from the translation 141 of Kim, Kim, \& Lee (1999), Tanikawa (2007), and Zhu \& Zhang (2011). Color images of the female, 142 dorsal and lateral aspects, and the male are provided in Yaginuma (1960: 67, Plate 29, Fig. 163).

143 Distribution. Nephila clavata is found throughout Japan (except the island of Hokkaido),

144 Korea, China, and Taiwan (Kim, Kim, \& Lee, 1999). The World Spider Catalog (2014) lists the 145 species as occurring from "India to Japan."

Material examined - New North American records (Fig. 2). UNITED STATES:

147 GEORGIA: Barrow Co., Hoschton, 31-x-2014, C. Robbins, 5 females [34.089846, -83.8266]. Jackson 148 Co., Braselton, 31-x-2014, R. Barbani, 2 females \& egg sac [34.138962, -83.798877]; Braselton, 149 Braselton Park, 4-xi-2014, GMNHTC 12242, E. R. Hoebeke and B. J. Freeman, 2 females \& 2 males 150 [34.1072909, -83.7638141]; Braselton, 9-xi-2014, K. Youngblood (image only) [34.142209, 151 83.7564699]; Hoschton , 4-xi-2014, C. Glick (image only) [34.064256, -83.693733]; Hoschton, 4-xi152 2014, K. and J. Howell, 1 female [34.093613, -83.747015]; Jefferson, 4-xi-2014, C. Hamilton, 1 153 female [34.097902, -83.6953489]. Madison Co., Colbert, 4-x-2014, GMNHTC 12241, W. Huffmaster, 1541 female [34.073869, -83.2742425]; Comer, 7-xi-2014, K. Fields, 1 female [34.0878353, 155 83.1133751].

156 Bionomics and habitat. Nephila clavata is univoltine in Japan. Eggs overwinter and 157 spiderlings emerge from the egg cocoons in early June in central Japan (Miyashita, 1986, 1990; 158 Miyashita \& Hayashi, 1996). Males reach maturity by late August and females become sexually 159 mature in September and early October. After mating, oviposition occurs from mid October to 160 November resulting in the production of only a single egg sac (Miyashita \& Hayashi, 1996). Adult 161 males do not construct their own webs but join females on their webs (Miyashita, 1994; Miyashita \& 162 Hayashi, 1996). Females produce large, golden-yellow, basket-shaped webs between tree branches. 
163 Females oviposit between 400-500 eggs in a single egg sac (Kim, Kim, \& Lee, 1999), inside a densely

164 woven silk cocoon that is attached to the bark of trees, on leaves, or upon other human-made

165 structures. Harvey, Austin, \& Adams (2007) described the production of a non-viscid, dense, silk

166 platform upon which an egg sac is deposited, followed by the placement of a thick layer of bright

167 yellow, loose, flocculent or looped silk over the egg mass. In Korea, spiders are still active until late

168 November. All adults die off with the onset of winter. Kim, Kim, \& Lee (1999) noted that this species

169 inhabits mountainsides, fields, or is found in urban and non-urban woodland sites in its native habitat.

170 In Japan, spiders are commonly found throughout lowland forests and can also inhabit building spaces

171 in the vicinity of small urban woods (Miyashita, 1990), especially where there is a high degree of

172 human disturbance.

173 In northeast Georgia, large, mature females were first observed beginning in late September and

174 persisted until mid November when temperatures began to cool significantly. Most spiders were found

175 in large webs attached to the exterior of homes near porch lights, on wooden decks, or among shrubs

176 and flowering bushes near to homes. At one location in early November, spiders were found in webs

177 attached to small trees and high weeds along a wooded area of a small city park (Braselton Park,

178 Braselton). Here we also found two males in a web with a single female. At one Braselton home site,

179 we found an egg sac, covered by a dense cocoon of silk and guarded by a female, attached to vinyl

180 siding of a home.

181 DNA barcoding. The two COI sequences recovered in this study were aligned with GenBank

182 Popset (537470784) consisting of forty-four taxa of Orbiculariae (Kuntner et al., 2013) and eight

183 additional sequences for $N$. clavata retrieved from Genbank (Su et al., 2011; Arabi et al., 2012), and

184 unpublished. A phylogeny (Fig. 3) based on COI sequence data was performed using Mr. Bayes

185 3.2.2 (Huelsenbeck and Ronquist, 2001) as implanted in Geneious 8.05. The outgroup was the

186 European cave spider Meta menardi (Latreille). Mr. Bayes parameters included the HKY85

187 substitution model, a run length of 1,100,000 generations, subsampling frequency of 200 and

188 burn-length of 100,000. All Nephila clavata sequences were recovered in a monoplyletic clade with

189 a posterior probability of 1.0. A comparison of aligned sequences for $N$. clavata revealed two groups

190 with differing haplotypes at positions 309 and 318 with this alignment motif. One group, represented

191 by GenBank accession numbers: KC849082, AY052586, JN032336, HQ441927, JN817136, and

192 AB917973, has Adenine at position 309 and Guanine at position 318, and the second group represented

193 by KJ577713, KP226137, KP226138, HQ441928 and HQ441929 has Guanine at position 309 and 
194 Thymine at position 318. Sequences from Georgia specimens GMNHTC 12241 (GenBank KP226137) and GMNHTC 12242 (GenBank KP226138) were identical.

\section{DISCUSSION}

Hundreds of non-native species of animals and plants have been inadvertently introduced into managed landscapes and natural ecosystems of North America. In fact, an estimated 2,000+ species of insects and arachnids have become established in North America over the past half-century and largely attributable to a dramatic increase in travel and international commerce (OTA, 1993). To date, approximately 60 species of non-native spiders (Araneae) have been detected in North America, with the majority originating from Europe and Asia (a species list of adventive spiders in North America is posted at http://bugguide.net/node/view/32329\#Anchor_Araneae). Nephila clavata becomes the newest species to be added to this list of non-native spiders occurring in North America.

Potential pathways of introduction. Accidental human transport of spiders and their egg masses on or within cargo containers, on plant nursery stock and on crates and pallets (Nentwig \& Kobelt, 2010), can explain and account for the presence of many European and Asian species in North America. We think this is the probable means of transport by which $N$. clavata gained entry. If accidental transport of $N$. clavata were to occur in late August to early October from countries of origin in East Asia, then the spiders' reproduction would be at its height and there would be a greater likelihood that egg sacs might be deposited on structures or plant material being exported.

Country of origin. Sequence data for the COI gene recovered from these Georgia specimens confirms our identity of $N$. clavata, by comparison with published sequences from nine different Asian populations of $N$. clavata, and suggests that specimens recorded from Georgia are more closely related to sources in China or Japan, rather than Taiwan, based on unique haplotypes. The Georgia specimens sequenced span the geographical range of our records suggesting that they share the same source. The Yunan (HQ441928) and Huaining (KJ577713) China specimens are over 1,500 km distant from each other and the Saitama, Japan population (HQ441929) is over 4,000 km from Yunan, and all of these sequences are identical for about 700 base pairs of COI, and they share the same variable haplotypes as the Georgia specimens. Specimens from Xiaguan, China (KC849082), Kaohsiung, Taiwan (HQ441927), and unspecified Asian locations (AY052586, JN 032336, JN817136, and AB917973) 
224 share a different set of variable haplotypes from the Georgia specimens, and also span a similarly broad 225 geographic range.

226 Dispersal opportunities. Once spider populations have successfully colonized in a given

227 location, individual spider movement might be best explained by the movement of transport vehicles

228 along major rail or road corridors (Nentwig \& Kobelt, 2010) or possibly by ballooning of spiderlings in

229 the spring after egg hatch. Ballooning is a behavior by which spiders use air-borne dispersal to move

230 between locations. Depending on mass and posture, a spider might be taken up into upper air streams

231 (Suter, 1992), while its aerial movement would be dependent on convection air currents and on the

232 drag of the silk parachute (Greenstone, Morgan, \& Hultsh, 1987). Members of the genus Nephila have

233 been suggested by some (Kuntner \& Agnarsson, 2011; Su et al., 2011) to be among the best spider

234 dispersers via their ballooning behavior.

235 A preponderance of sightings and collection of specimens of $N$. clavata were centered on a

236 restricted area in and around Braselton and Hoschton, GA. One property owner in Hoschton indicated

237 that the spider had been present around her home for at the past 4 years. We are not necessarily

238 suggesting that this area represents the probable arrival point of this Asian spider, but it could be

239 argued that the industrial and business history of the region might demonstrate it to be a possibility.

240 The town of Braselton is a thriving business location on the I- 85 business corridor, located $64 \mathrm{~km}$

241 northeast of Atlanta. As such, its location on the I-85 corridor provides excellent transportation access.

242 It is home to many warehousing and distribution facilities that transport containerized freight from 243 overseas.

244 Collection locales in Jackson and Barrow counties $(n=7)$ are clustered on the I- 85 corridor but

245 the Madison county records $(\mathrm{n}=2)$ are located in a rural mixed farm landscape, not adjacent to

246 commercial transportation corridors. The Madison county sites are ca. $50 \mathrm{~km}$ due west and downwind

247 from the other Barrow and Jackson county sites. We hypothesize that these downwind sites were

248 colonized by aerial dispersing spiderlings using the prevailing westerly winds and suggest that other

249 populations might be found along this route.

\section{ACKNOWLEDGMENTS}

253 We are indebted to the following individuals who alerted us to the presence of $N$. clavata around their

254 homes in northeast Georgia; their e-mails, with attached digital images of the spider, allowed us to 
determine the validity of their sightings: Ronald Barbani and Kelly Youngblood (Braselton); Christine Robbins, Kristin and Jeremy Howell, and Crystal Glick (Hoschton); Crystal Hamilton (Jefferson); and Kathy Fields (Comer). We also acknowledge Gang Hua and Qi Zhang (Department of Entomology, University of Georgia) and Tae-young Lee (Entomology, UGA) for helping with the translation Chinese to English and Korean to English, respectively - of taxonomic passages in the Asian spider literature; Kent Loeffler (Chico, CA) for assistance with digital image enhancement, editing, and layout for Fig. 1; and Mary Freeman (U.S. Geological Survey, Athens, GA) and Carrie Straight (USFWS, Athens, GA) for generating the ArcGIS map of known spider localities in Fig. 2. We also thank the Wares Lab (Department of Genetics, University of Georgia) for advice, engaging discussions, and use of equipment, as well as Matjas Kuntner (Slovenian Academy of Sciences and Arts, Ljubljana, Slovenia) and two anonymous reviewers for valuable suggestions that improved an early draft of the manuscript.

\section{REFERENCES}

Alvarez-Padilla F, Dimitrov D, Giribet G, Hormiga G. 2009. Phylogenetic relationships of the spider family Tetragnathidae (Araneae, Araneoidea) based on morphological and DNA sequence data. Cladistics 25: 109-146.

Arabi J, Judson ML, Deharveng L, Lourenco WR, Cruaud C, Hassanin A. 2012. Nucleotide composition of $\mathrm{CO} 1$ sequences in Chelicerata (Arthropoda): detecting new mitogenomic rearrangements. Journal of Molecular Evolution 74 (1-2): 81-95.

Blaxter ML. 2004. The promise of a DNA taxonomy. Philosophical Transactions of the Royal Society B: Biological Sciences 359: 669-679.

Casquet J, Thebaud C, Gillespie RG. 2012. Chelex without boiling, a rapid and easy technique to obtain stable amplifiable DNA from small amounts of ethanol-stored spiders. Molecular Ecology Resources 12: 136-141.

Dimitrov D, Hormiga G. 2009. Revision and cladistic analysis of the orbweaving spider genus Cyrtognatha Keyserling, 1881 (Araneae, Tetragnathidae). Bulletin of the American Museum of Natural History 317: 1-140.

Feng ZQ. 1990. Spiders of China in colour. Hunan Science and Technology Publishing House. 256 pp.

Folmer O, Black M, Hoeh W, Lutz R, Vrijenhoek R. 1994. DNA primers for amplification of mitochondrial cytochrome c oxidase subunit I from diverse metazoan invertebrates. Molecular Marine Biology and Biotechnology 3: 294-299.

Greenstone MH, Morgan CE, Hultsh AL. 1987. Ballooning spiders in Missouri, USA, and New South Wales, Australia: Family and mass distributions. The Journal of Arachnology 15: 163-170. Hebert PDN, Cywinska A, Ball SL, deWaard, JR. 2003. Biological identifications through DNA barcodes. Proceedings of the Royal Society B 270: 313-321. 
Huelsenbeck JP, Ronquist F. 2001. MRBAYES: Bayesian inference of phylogenetic trees. Bioinformatics Applications Note 17:754-755.

Harvey MS, Austin AD, Adams M. 2007. The systematics and biology of the spider genus Nephila (Araneae: Nephilidae) in the Australasian region. Invertebrate Systematics 21: 407-451.

Kim JP, Kim SD, Lee YB. 1999. A revisional study of the Korean spiders, family Tetragnathidae Menge, 1866 (Arachnida: Araneae). Korean Arachnology 15(2): 41-100.

Kuntner M. 2005. Systematics and evolution of nephilid spiders (Araneae, Nephilidae new rank). Unpublished PhD thesis. Washington DC: George Washington University. pp 896.

Kuntner M. 2006. Phylogenetic systematics of the Gondwanan nephilid spider lineage Clitaetrinae (Araneae, Nephilidae). Zoologica Scripta 35: 19-62.

Kuntner M, Agnarsson I. 2011. Phylogeography of a successful aerial disperser: the golden orb spider Nephila on Indian Ocean islands. BMC Evolutionary Biology 11:119. doi:10.1186/14712148-11-119..

Kuntner M, Arnedo MA, Trontelj P, Lokovsek T, Agnarsson I. 2013. A molecular phylogeny of nephilid spiders: evolutionary history of a model lineage. Molecular Phylogenetics and Evolution 69: 961-979.

Kuntner M, Coddington JA. 2009. Discovery of the Largest Orbweaving Spider Species: The Evolution of Gigantism in Nephila. PLoS ONE 4(10): e7516. doi:10.1371/journal.pone.0007516.

Kuntner M, Coddington JA, Hormiga G. 2008. Phylogeny of extant nephilid orbweaving spiders (Araneae, Nephilidae): testing morphological and ethological homologies. Cladistics 24: 147217.

Kuntner M, Gregoric M, Li DQ. 2010. Mass predicts web asymmetry in Nephila spiders. Naturwissenschaften 97: 1097-1105.

Mack RN, Simberloff D, Lonsdale WM, Evans E, Clout M, Bazzaz FA. 2000. Biotic invasions: causes, epidemiology, global consequences, and control. Ecological Applications 10: 689-710.

Miyashita T. 1986. Growth, egg production, and population density of the spider Nephila clavata in relation to food conditions in the field. Researches on Population Ecology 28: 135-149.

Miyashita T. 1990. Decreased reproductive rate of the spider, Nephila clavata, inhabiting small woodlands in urban areas. Ecological Research 5: 341-351.

Miyashita T. 1994. Size-related mating and mate guarding in the orb-web spider Nephila clavata (Araneae, Araneidae). Journal of Insect Behavior 7: 289-296.

Miyashita T, Hayashi H. 1996. Volatile chemical cue elicits mating behavior of cohabiting males of Nephila clavata (Araneae, Tetragnathidae). The Journal of Arachnology 24: 9-15.

Nentwig W, Kobelt M. 2010. Spiders (Araneae). Chapter 7.3. BioRisk 4: 131-147. doi: 10.3897/biorisk.4.48

OTA 1993. U.S. Congress, Office of Technology Assessment. Harmful Non-indigenous Species in the United States (OTA-F-565). U.S. Government Printing Office: Washington, DC. 391 pp.

Pan HC, Zhou KY, Song DX, Qui Y. 2004. Phylogenetic placement of the spider genus Nephila (Araneae: Aranneoidea) inferred from rRNA and MaSp1 gene sequences. Zoological Sciences 21: 343-351.

Pan HC, Pan WJ. 2014. The complete mitochondrial genome of Nephila clavata (Araneae: Nephilidae) Chinese population. GenBank Accession KJ577713.

Su YC, Chang YH, Smith D, Zhu MS, Kuntner M, Tso IM. 2011. Biogeography and speciation patterns of the golden orb spider genus Nephila (Araneae: Nephilidae) in Asia. Zoological Science 28: 47-55. 
Suter RB. 1992. Ballooning: Data from spiders in freefall indicate the importance of posture. The Journal of Arachnology 20: 107-113.

Tanikawa A. 2007. An identification guide to the Japanese spiders of the families Araneidae, Nephilidae and Tetragnathidae. Arachnological Society of Japan. 121 pp.

Wares JP, Gaines SD, Cunningham CW. 2001. A comparative study of asymmetric migration events across a marine biogeographic boundary. Evolution 55: 295-306.

Waugh, J. 2007. DNA barcoding in animal species: progress, potential and pitfalls. Bioessays 29: 188-197.

Weems Jr, HV, Edwards GB. 2004. Featured Creatures - common name: golden silk spider, scientific name: Nephila clavipes (Linnaeus) (Arachnida: Araneae: Tetragnathidae). Department of Agriculture and Consumer Services, DPI Entomology Circular 193. Available at http://entnemdept.ufl.edu/creatures/misc/golden_silk_spider.htm (accessed 19 November 2014).

Wheeler Jr. AG, Hoebeke ER. 2009. Adventive (non-native) insects: importance to science and society, pp. 475-521. In RG Footitt and PH Adler (eds.), Insect Biodiversity. WileyBlackwell.

World Spider Catalog. 2014. World Spider Catalog. Natural History Museum Bern. Available at http://wsc.nmbe.ch. version 15.5 (accessed 14 November 2014).

Yaginuma T. 1960. Spiders of Japan in colour. Hoikusha, Osaka. 186 pp. [in Japanese]

Zhu MS, Zhang BS. 2011. Spider Fauna of Henan: Arachnida: Araneae. Science Press, Beijing. xxii + $558 \mathrm{pp}$.

Zhu MS, Song DX, Zhang JX. 2003. Fauna Sinica: Invertebrata Vol. 35: Arachnida: Araneae: Tetragnathidae. Science Press, Beijing. vii +418 pp. 
364 Fig. 1. Photographic images of Nephila clavata suspended in its web in northeast Georgia, taken in 365 October 2014. A, female, dorsal aspect; scale bar $=30 \mathrm{~mm}$. B, female, lateral aspect. C, female, ventral 366 aspect. D, male, dorsal aspect; scale bar $=5 \mathrm{~mm}$. Photos A-C were taken in Hoschton, GA by Jeremy 367 Howell; photo D was taken in Braselton, GA by B. J. Freeman. 
370 Fig. 2. Map of Georgia, U.S.A. A, geocoded localities in Barrow, Jackson, and Madison counties, 371 about $64 \mathrm{~km}$ northeast of Atlanta, where collections and sightings of Nephila clavata were made. B, 372 location of the above-mentioned counties in northeast Georgia.

373

374

375

376

377

378

379

380

381

382

383

384

385
Fig. 3. Bayesian phylogeny based on COI sequences for 52 individuals of Orbiculariae. The outgroup is Meta menardi. Posterior probabilities are presented at each node. Species names are followed by GenBank numbers. The Nephila clavata clade is shaded blue and labeled A with the country of origin following each sequence. 
1

Photographic images of Nephila clavata suspended in its web in northeast Georgia, taken in October 2014.

A, female, dorsal aspect; scale bar $=30 \mathrm{~mm}$. B, female, lateral aspect. C, female, ventral aspect. D, male, dorsal aspect; scale bar $=5 \mathrm{~mm}$. Photos A-C were taken in Hoschton, GA by Jeremy Howell; photo D was taken in Braselton, GA by B. J. Freeman. 
PeerJ Reviewing Manuscript
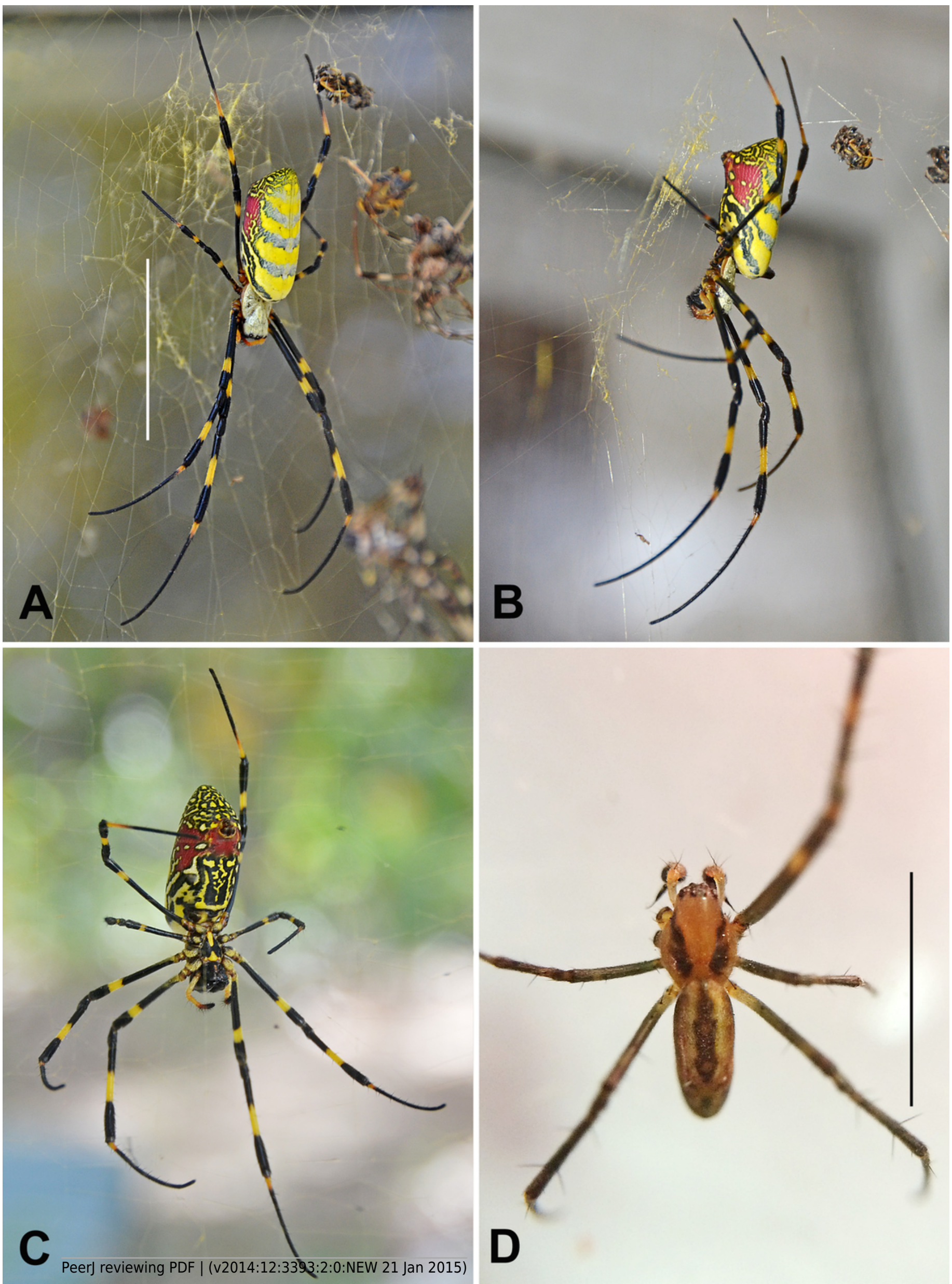
2

Map of Georgia, U.S.A.

A, geocoded localities in Barrow, Jackson, and Madison counties, about $64 \mathrm{~km}$ northeast of Atlanta, where collections and sightings of Nephila clavata were made. B, location of the above-mentioned counties in northeast Georgia. 


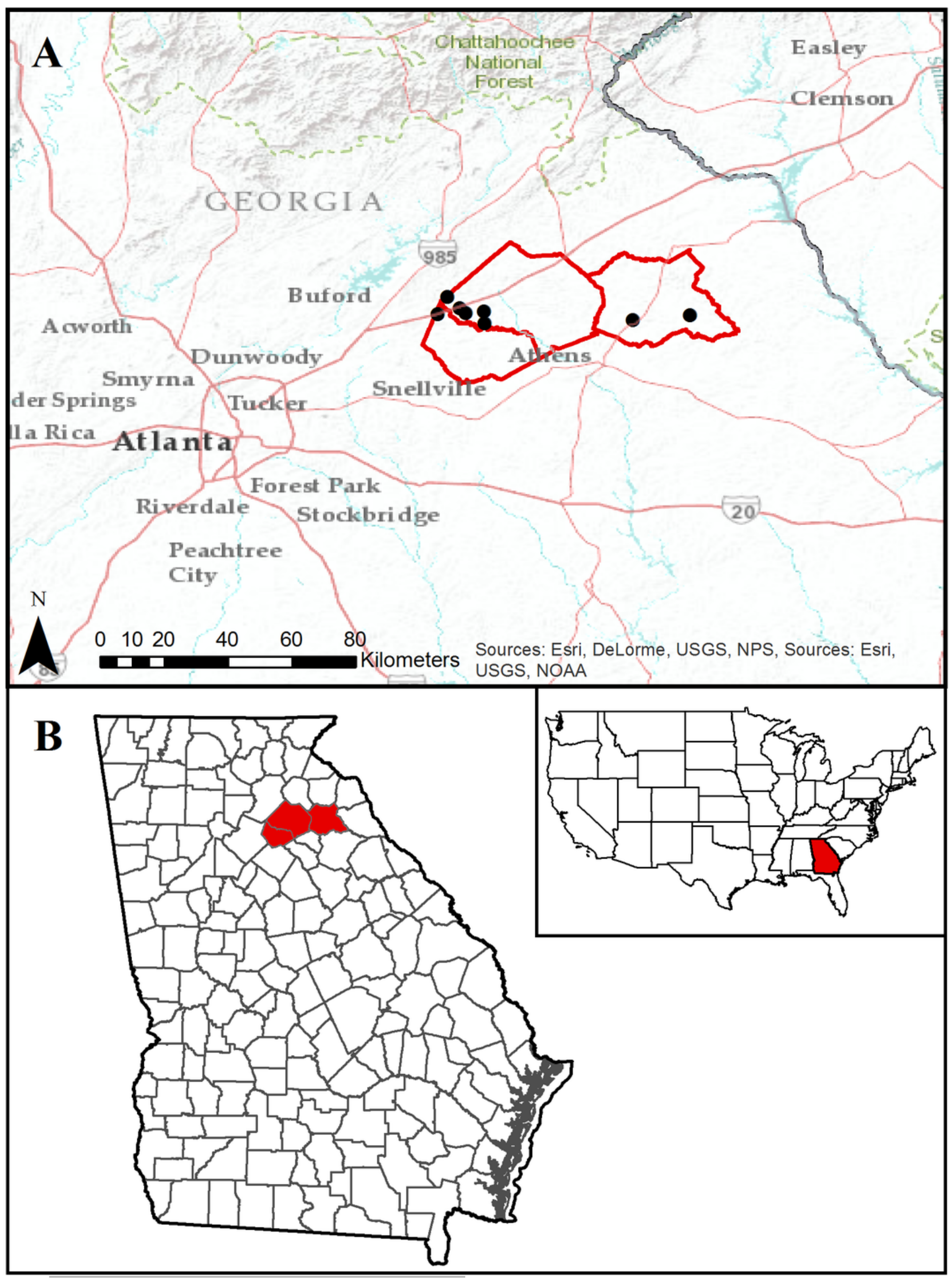




\section{3}

Bayesian phylogeny for 52 individuals of Orbiculariae

Bayesian phylogeny based on $\mathrm{COI}$ sequences for 52 individuals of Orbiculariae. The outgroup is Meta menardi. Posterior probabilities are presented at each node. Species names are followed by GenBank numbers. The Nephila clavata clade is shaded blue and labeled A with the country of origin following each sequence.

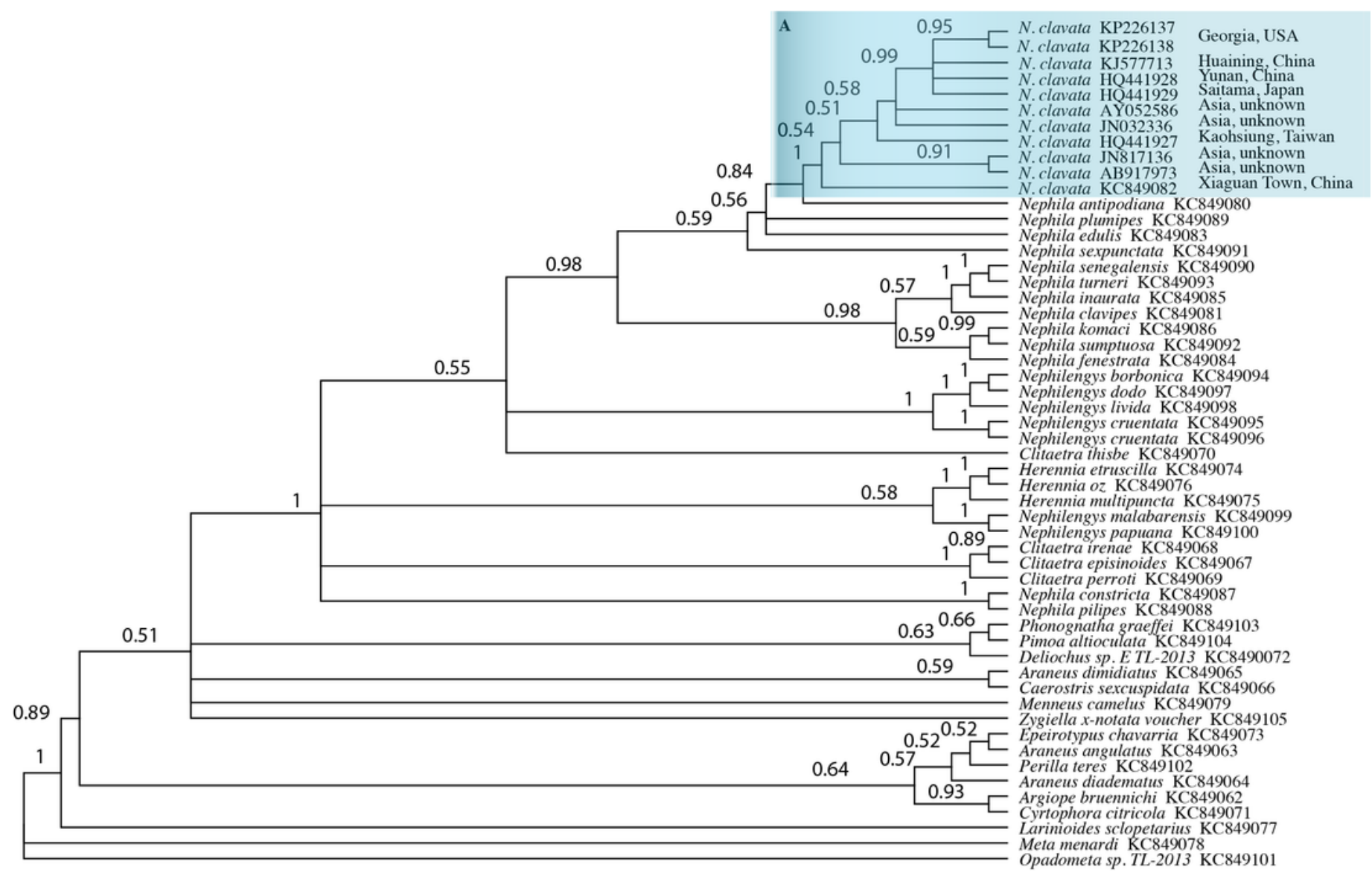

